\title{
IT Solution concept development for tracking and analyzing the labor effectiveness of employees
}

\author{
Igor Ilin, Svetlana Shirokova, Aleksandr Lepekhin
}

Peter the Great St. Petersburg Polytechnic University, Institute of Industrial management, Economy and Trade, 195251, Polytechnicheskaya, 29, St.Petersburg, Russia

\begin{abstract}
Labor efficiency and productivity of employees is an important aspect for the environment within any type of organization. This is particularly crucial factor for the companies, if which operations are associated with physical labor, such as construction companies. Productivity and efficiency are both very complicated concepts and a huge variety of methods and approaches to its analysis can be implemented within the organization. Despite that, it is important to choose the methods, which not only analyze the key performance indicators of employee, but take into account personal indicators, which might affect performance even more than professional skills. For this complicated analysis task it is important to build IT solution for tracking and analyzing of the labor effectiveness. The concept for designing this IT solution is proposed in the current research.
\end{abstract}

\section{Introduction}

All around the world, large companies are trying to provide an appropriate combination of approaches for increasing the effectiveness of staff (for example, by increasing labor productivity) and reducing injuries of employees.

In high-rise construction, this problem is most acute, as they appear to be complex systems with different types of internal challenges [1]. On one hand, It is necessary to secure the employees, to predict the state of their ailment. On another hand, it is important to increase the effectiveness of their activities, interactions and day-to-day operations.

It is not surprising that currently this topic is especially relevant, because increasing the efficiency of workers means new opportunities for the company, while the competitive environment puts considerable pressure on the company's development [2]. Thus, it is necessary to propose different approaches to the analysis of efficiency and productivity of labor in a direct relationship with the continuous analysis of the worker's physical condition and compare these indicators.

This research paper addresses:

- Different approaches to the analysis of the efficiency and productivity of working process,

- Comparative description of the approaches and the proposal of necessity of developing an IT solution using the most appropriate approach, 
- The necessity of implementation of a monitoring module for analysis of the physical condition of the employee.

The goal of the research is the development of an integrated approach as the basis for an IT solution that combines an analysis of approaches to the evaluation of productivity in combination with methods for assessing the capabilities and physical condition of staff [38]. The research structure is the following. The second chapter addresses the analysis of different approaches to evaluation of labor productivity. The third chapter analyses the applicability of Biological feedback approach to tracking and improving the labor productivity. The Discussion and Conclusion parts summarize the results of the current research.

\section{Materials and methods}

Current chapter presents an analysis of approaches to the evaluation of labor productivity, which aims to increase the efficiency and productivity of daily activities of employees to further create an IT solution that uses the most appropriate method.

The research methodology consists of:

- identifying of various existing approaches to the evaluation of labor productivity;

- conducting a direct analysis with the identification of key features;

- providing the choice of approach to assessing the performance of intellectual work.

When choosing approaches to solving scientific and technical problems, one of the main criteria is the ability of one or another approach to create value for consumers of products by increasing labor productivity [3-5].

Another criterion is the theoretical basis of the approach, the existence of a practical experience confirming the practical feasibility of the method.

A number of studies have been carried out, on the basis of which it is possible to optimize labor productivity. Labor productivity analysis can be performed using several approaches, such as:

- Economic approach,

- Biometric approach,

- Analysis of external factors (manifestations of human activities),

- Biological feedback approach (BFD).

Figure 1 demonstrates the reasons for choosing an approach to analyzing labor productivity [6].

Each approach was studied and its concept was disclosed.

The economic essence of labor productivity lies in the fact that it is represented as a function of real labor, which means that it is an indicator of evaluation and a criterion for the efficiency of production. The growth of labor productivity allows increasing production volumes and creating conditions for the further development of the economy [3].

Balanced Scorecard (BSC) is one of the most popular and universally accepted concept of managing the implementation of the strategy developed by the professors of Harvard University D. Norton and R. Kaplan (USA). BSC - is a mechanism for the consistent delivery of strategic success factors to the staff, the company's goals and monitoring of their achievement through key performance indicators.

KPI is an indicator of the attainability of the goals set, as well as the characteristics of the effectiveness of business processes and the work of each individual employee. KPI and staff motivation make it possible to implement the company's strategy, described and formalized using of BSC [10].

This approach involves measuring the economic performance of the organization, while labor productivity is treated as an economic indicator that characterizes the participation of an individual employee in the company's financial performance. 


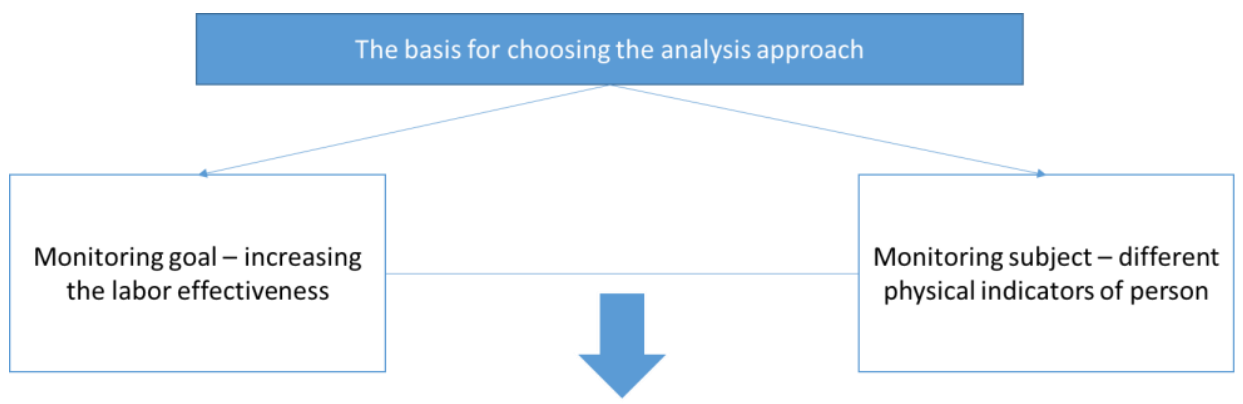

\section{APPROACHES}

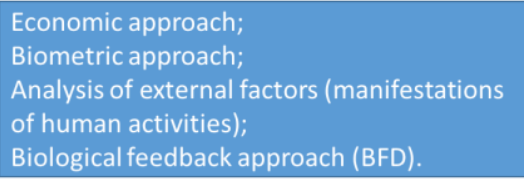

Fig. 1. Approaches to the analysis of the labor productivity.

However, this approach does not allow to optimize the individual daily activities of each employee. KPIs are used at a higher level of detail, both in terms of the organizational hierarchy and in terms of the planning horizon.

To track the individual contribution of the employee and monitor the personal effectiveness, measurements of a number of biometric parameters are used. The characteristics of biometric indicators are:

- Measurability,

- Resilience to the environment,

- Resistance to forgery,

- Accuracy of recognition.

The sources of information for this approach could be:

- Electroencephalogram,

- Electrical activity of the skin,

- Thermometry (surface temperature of the body),

- Photoplethysmogram and other.

Having obtained all the necessary data from the research, it will be necessary to create an information system that processes the data obtained and issues appropriate recommendations. For the procedure of complex examination, it is possible to use methods of organizing complex examinations $[7,10,11]$.

The problem is the need to compare the requirements for increasing the efficiency of labor, on the one hand, and the possibility and physical condition of the employee, on the other. These problems are associated with the need to analyze the effectiveness of approaches to assessing performance in conjunction with the assessment of physical state. The quantitative evaluation criteria are normally heterogeneous, so the problem of comparability of criteria arises.

As a result, there arises the need to create a system for organizing a complex examination based on the use of structuring methods that divide a large initial uncertainty into more visible parts. The information approach can be used to obtain estimates of the degree of influence of 
the approach to the performance evaluation taking into account a specific situation and to bring heterogeneous criteria (quantitative and qualitative) to unified information units for further comparison and analysis.

The Figure 2 illustrates an example of the assessment of the requirements for improving productivity, using different approaches, taking into account the physical characteristics of employees.

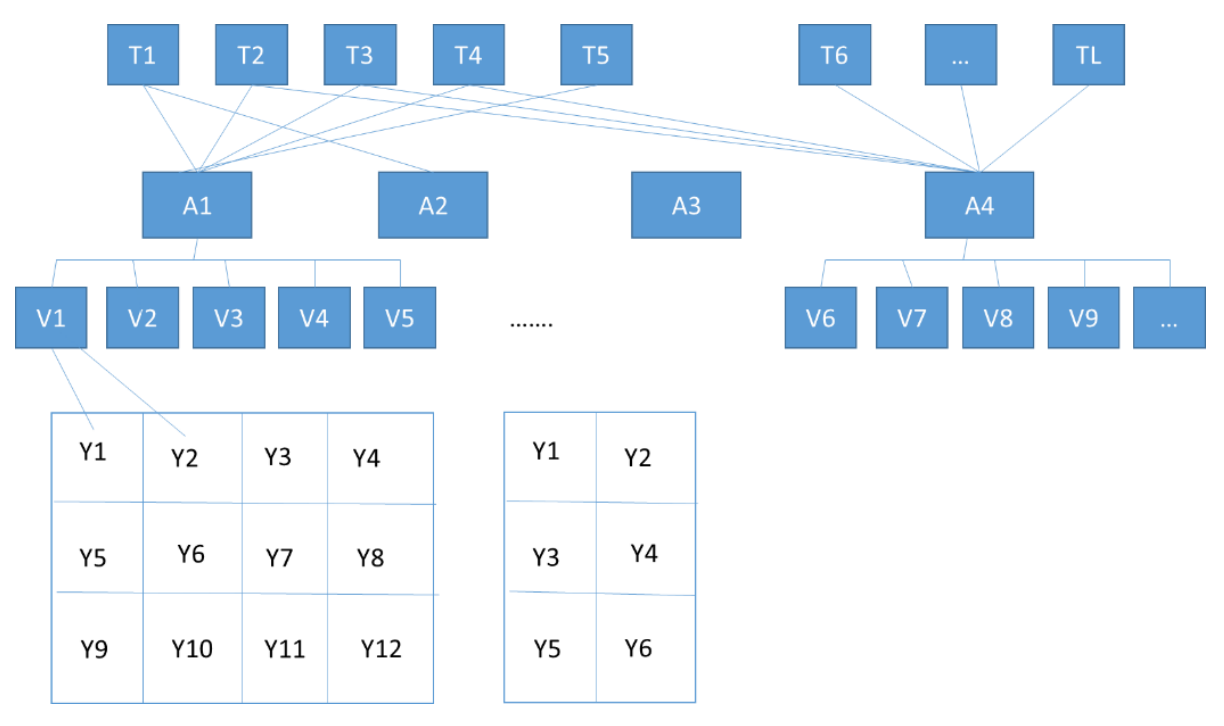

Legend: A1-A4 - approaches to the evaluation of labor productivity

T1---TL - parameters for assessing the physical condition of the employee - quantitative and qualitative; V1---VZ - groups used in the approach to assessing performance $\mathrm{Y} 1---\mathrm{Y}_{\mathrm{W}}$ components (a set of parameters) for assessing the physical state

Fig. 2. The method of organizing a complex examination, based on the information approach.

For the evaluation, you the quantitative criteria given in the upper part of Figure 2 can be used. But the qualitative characteristics are important, they can only be quantified only partially.

When assessing by qualitative criteria, pi' is determined as a degree of influence of iparameter of evaluation of a person's condition or taking into account the use of the iparameter when assessing the physical state in a situation.

\section{Results}

Analysis based on external factors involves a set of methods and tools that allow you to register and process data from the external manifestation of human activity. Data can be used:

- Movement activities of the user,

- Electromyograms,

- Oculograms,

- And other.

The investigated parameters can be used for analysis of mental activity, emotional stress, employee fatigue. 
Audit of user activity is possible with the help of specially developed software applications, which have the following functions:

1. Register a record of user actions in the storage of space-time data of the system;

2. Form arbitrary reporting based on accumulated data

Biological feedback is a method of changing the psychophysiological state of a person. It is based on an individual approach, the choice of an individual standard of the optimal psychophysiological state and on this basis the definition and current correction of the tactics of its change [7].

Biological feedback aims to track and analyze the following indicators as well as their influence the overall labor intensity and effectiveness:

- Heart rate,

- Breathing rate,

- Skin galvanic reaction.

Table 1 demonstrates the summary analysis of different approaches.

Table 1. Strong and weak points for labor intensity analysis.

\begin{tabular}{|c|c|c|c|c|}
\hline & $\begin{array}{l}\text { Economic } \\
\text { approach }\end{array}$ & Biometric approach & $\begin{array}{l}\text { Analysis of } \\
\text { external factors }\end{array}$ & $\begin{array}{l}\text { Biological } \\
\text { feedback }\end{array}$ \\
\hline $\begin{array}{l}\text { Strong } \\
\text { points }\end{array}$ & $\begin{array}{l}\text { KPI } \\
\text { implementation }\end{array}$ & $\begin{array}{l}\text { Monitors personal } \\
\text { effectiveness }\end{array}$ & $\begin{array}{l}\text { A set of methods and } \\
\text { tools that allow } \\
\text { processing the data } \\
\text { of the external } \\
\text { manifestation of } \\
\text { human activity is } \\
\text { used. }\end{array}$ & $\begin{array}{l}\text { The active } \\
\text { participation of a } \\
\text { person in his } \\
\text { training in the } \\
\text { management of } \\
\text { the functions of } \\
\text { his own organism. }\end{array}$ \\
\hline $\begin{array}{l}\text { Weak } \\
\text { points }\end{array}$ & $\begin{array}{l}\text { It does not allow to } \\
\text { optimize the } \\
\text { individual daily } \\
\text { activities of each } \\
\text { employee; }\end{array}$ & $\begin{array}{l}\text { Only physical } \\
\text { indicators of } \\
\text { employees are taken } \\
\text { into account, all other } \\
\text { aspects are ignored }\end{array}$ & $\begin{array}{l}\text { There may be a } \\
\text { feeling of "excessive } \\
\text { observation" }\end{array}$ & Not detected \\
\hline
\end{tabular}

Inclusion of these models in the procedure of integrated assessment made it possible to formulate a procedure for determining the effectiveness of activities taking into account the physical condition of a person. 


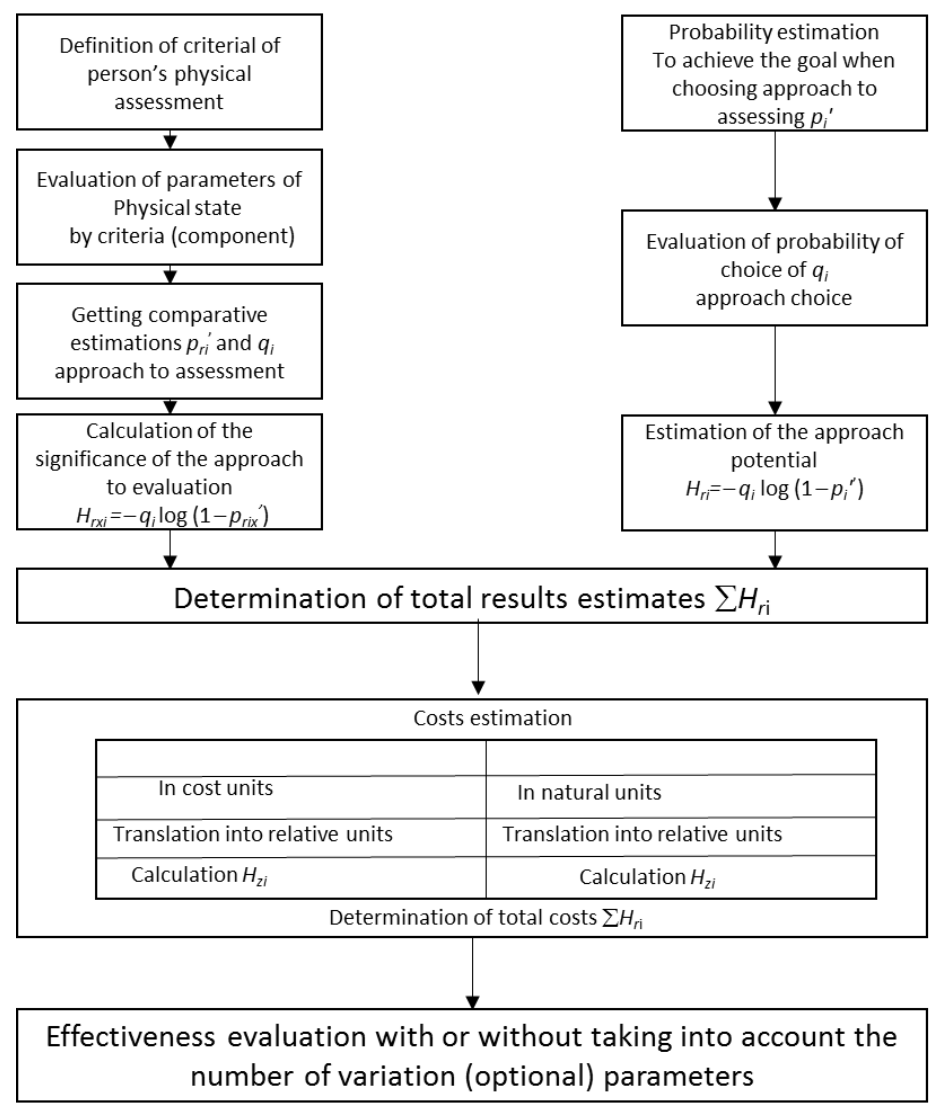

Fig. 3. The algorithm of the integrated assessment procedure.

The proposed algorithm of Hi estimation based on pi results in the following advantages of the proposed approach:

- Not only $p_{i}{ }^{\prime}$ (degree of influence) can be taken into account, but also $q_{i-}$ The probability of taking this parameter into account in the complex estimation,

- Simplification to obtain generalized estimates of the impact of options or their components on the implementation of sub-goals.

The developed integrated assessment procedure is the basis for developing an IT solution. Joint use of methods of organizing complex examinations and BFD technologies allows one to effectively approach the solution of the problem of increasing the efficiency of labor taking into account the physical condition of the employee in this situation. This allows you to develop a software and hardware system.

\section{Discussion}

Evaluating the information presented in different studies and taking into account the problem nature, it can be concluded that the convenient approach to track personal labor intensity is the Biological feedback approach. The method provides an instrument for the disclosure and use of body reserves, organically fits into any scheme for improving the quality of life and improving health. The use of Biological feedback technologies is a promising way to increase labor productivity, since it allows to regulate the cognitive load 
and the psycho-emotional state of a person. This aspect is rarely addressed in the existing literature yet. Few research paper proposed an importance of personal indicators analysis and their influence of work performance and, as a result, on productivity and organizational environment [12]. Some studies even focus on relation between health risks and work productivity, which means that there is potential for further research and analysis [13]. The systematic assessment, proposed in this paper, could enable a comprehensive assessment of productivity and efficiency, taking into account the physical state and using biological feedback. This approach could also complement different approaches to enterprise development, such as enterprise architecture projects, in terms of human resources development [14].

The development of IT solutions using this approach might improve the efficiency and productivity of work. The design and development of IT services for tracking personal indicators could become the direction for future research.

\section{Conclusions}

The research paper addressed the problem of labor productivity and efficiency, which is specifically important for construction companies because of high labor intensity among employees. It was proposed that in order to increase the efficiency and productivity, it is particularly important to track and analyze different indicators of employee's performance. Different methods were studied and the concept of algorithm of the integrated assessment procedure was proposed. This concept summarizes different personal indicators and methods of their tracking and analysis. The proposed ideas could further become the basis for IT services development, which would have potential for tracking, analyzing and increasing labor efficiency.

\section{References}

1. I. Ilin I.V., et al, MATEC Web of Conferences. 83. 05028 (2016)

2. A.Bril A.R., Kalinina O.V., Ilin I.V. (2017) MATEC Web of Conferences, 106, 08010, International Science Conference SPbWOSCE-2016 "SMART City".

3. M.Koch, M. J., \& McGrath, R. G. (1996). Improving labor productivity: Human resource management policies do matter. Strategic management journal, 335-354.

4. V. Volkova et al. Proceedings of the 19th International Conference on Soft Computing and Measurements, SCM 2016 2016. C. 470-473

5. S. Brody, Biofeedback and SelfRegulation, Vol. 19, 1-13 (1999)

6. A.Rice, A. L. (Ed.). (2013). The enterprise and its environment: A system theory of management organization (Vol. 10). Routledge.

7. J. Freeman, J. A. (1975). U.S. Patent No. 3,890,957. Washington, DC: U.S. Patent and Trademark Office.

8. M. Shvartsman, M., Srivastava, V., \& Cohen, J. D. (2015). A theory of decision making under dynamic context. In Advances in neural information processing systems (pp. 2485-2493)..

9. S. Alter, S. (2015). Work system theory as a platform: response to a research perspective article by Niederman and March. Journal of the Association for Information Systems, 16(6), 485.

10. T. Alesinskaya, et al (2017). Conception Bsc for Investment Support of Port and Industrial Complexes. Academy of Strategic Management Journal, 16, 9A. 
11. A. Bril et al Proceedings of 2017 20th IEEE International Conference on Soft Computing and Measurements, SCM 2017. 6 July 2017, Paper number 7970692, Pages 692-693

12. J. Collins, et al. (2005). The assessment of chronic health conditions on work performance, absence, and total economic impact for employers. Journal of Occupational and Environmental Medicine, 47(6), 547-557.

13. G. Johns, G. (2010). Presenteeism in the workplace: A review and research agenda. Journal of Organizational Behavior, 31(4), 519-542.

14. I. Ilin, I.V., Levina, A.I., Iliashenko, O.Yu. Enterprise architecture approach to mining companies engineering. 2017 MATEC Web of Conferences, 106, 0806 